\title{
Journal of Surgery and Surgical Research
}

\section{Ousmana Oumarou', Tchuenkam W Landry ${ }^{2 *}$, Njweipi C Joe', Festus T Wirwah ${ }^{2}$, Bisay S Ulrich ${ }^{2}$ and Engbang $\mathbf{N}$ Jean-Paul ${ }^{1}$}

'Department of Surgery, Douala Laquintinie Hospital, Douala, Cameroon

${ }^{2}$ Faculty of Medicine and Biomedical Sciences,

University of Yaoundé I, Cameroon

Received: 24 January, 2018

Accepted: 30 January, 2019

Published: 31 January, 2019

*Corresponding author: Tchuenkam W Landry, Faculty of Medicine and Biomedical Sciences, University of Yaounde I, Cameroon, Tel: +237 691528498;

E-mail: landrytchuenkus@gmail.com

Keywords: Pregnancy; Penetrating wound;

Evisceration; Fetal trauma

https://www.peertechz.com

Check for updates

\section{Case Report}

\section{Abdominal stab wound in A Pregnant}

woman resulting in Evisceration, Uterine

Perforation and Fetal Chest Injury: A

\section{Case Report and Literature Review}

\section{Abstract}

Introduction: trauma is common in pregnancy; it affects one in twelve pregnancies. Abdomen represents the third anatomical region of the body most affected after the limbs and head. As pregnancy evolves, uterus increases in size and goes beyond the pelvic cavity; exposing the uterus to trauma and penetrating injuries in particular. Penetrating abdominal trauma in pregnancy requires a rigorous clinical evaluation to establish a complete assessment of obstetric and non-obstetric lesions. It is an obstetrical emergency whose management depends on the abnormalities found. In case of major trauma, it is essentially carried out in a trauma center, with a multidisciplinary team to improve the maternal and fetal prognosis.

Case presentation: the authors report the case of a 28-year-old black woman, semi-Bantu, at 30 weeks gestation. She was referred to the emergency department of Douala Laquintinie Hospital for a penetrating wound of the abdomen after being stabbed at home. There were bowels protruding from the stabbed abdomen. The initial clinical assessment revealed hemodynamic instability, evisceration associated with bowel perforation, absence of active fetal movements, and absence of fetal heart sound from Doppler. An emergency laparotomy was performed. At the end of the surgical intervention, the following lesions were indentified: penetrating wound of the abdomen with evisceration, intestinal perforation, uterine perforation, fetal penetrating chest injury and fetal death.

Conclusion: this case report focuses on the spectrum of non-obstetric, obstetric and fetal injuries that may occur as a result of a penetrating stab wound in a pregnant woman.

\section{Abbreviations}

GSW: Gun Shoot Wound; DLH: Douala Laquintinie Hospital; cm: centimeter; dl: deciliter; g: gram

\section{Background}

In general, trauma is a major cause of mortality and morbidity worldwide, $[1,2]$ and is therefore a public health problem. It represents the first presenting complaint at emergency units in both developed and developing countries, with $80-89 \%$ of the reasons for emergency admissions [3]. Several mechanisms may be responsible for trauma: road traffic accidents on top of the list [4], with nearly 1.25 million deaths recorded in 2014 [4]. More than 45 million peoples worldwide suffer from moderate to severe disability each year due to trauma [1]. According to WHO estimates, by 2030 trauma will be the third leading cause of death in the world $[1,4]$.
The abdomen is frequently involve in trauma and consists of severe consequences in terms of morbidity and mortality. The proportion of damage to the abdomen during trauma remains variable, from 3.5 to $25 \%[3,5,6]$. Abdominal trauma is classified as blunt trauma or abdominal stab wounds. These can be non-penetrating or penetrating when they pass through the peritoneal cavity. The epidemiology differ greatly by geographic region; however, all studies agree on the higher incidence of blunt abdominal trauma in the civilian population compared to penetrating lesions, which can account for approximately 10 to $30 \%$ of abdominal traumatic injuries $[7,8]$. Penetrating lesions can be stabbed or gunshot in up to $15 \%$ of the series [7].

The morbidity and mortality after trauma of the abdomen is variable, ranging from $5 \%$ to $11 \%$ in terms of deaths $[2,9]$; admission and management in a trauma center is an independent factor in reducing mortality and morbidity [10]. Other factors are associated with a poor outcome in penetrating 
lesions of the abdomen: The presence of shock, a long interval between the incident and surgery, the associated lesions [9,11]; we also cite comorbidities, extreme ages and pregnancy.

During pregnancy, the anatomical and physiological changes make the management of trauma complex [12]. Regardless of the causative agent and the area of the body concerned, the trauma occurs approximately one out of a dozen pregnancy [13]; it is a non-obstetrical cause of maternal and fetal death [14]. Road traffic accidents [15], represent the mechanism most often involved ( $74 \%$ of cases), stabbing attacks are rare in pregnancy, less than $2 \%$ of causes of trauma [16]. With a frequency of $13 \%$, the abdomen is the third most affected anatomical region after the limbs and the head. Damage to the abdomen in case of trauma strongly affect the maternal and fetal prognosis; In fact, the mortality in pregnancy during abdominal trauma according to series is close to $3 \%$ in the mother and $16 \%$ in the fetus [17]; this rate increases significantly to $7 \%$ in the mother and $73 \%$ in the fetus when it is a penetrating injuries of the abdomen [17].

Maternal and fetal injuries generated during trauma result in spontaneous abortions, premature births, increased caesarean section rates and fetal deaths as fetal complications [18]. Therefore, aggressive maternal resuscitation in general is the best treatment for the fetus $[12,18]$. The spectrum of traumatic lesions of the abdomen in pregnant women varies depending on the gestational age [15]; uterus is usually involved, followed by intestinal loops.

We report here a case of abdominal stab wound with direct maternal intestinal and uterine lesions as well as direct fetal chest lesions in a 30 weeks pregnant woman.

\section{Case Presentation}

This is the case of a 28-year-old black woman of semiBantu ethnic group, housewife, married, at 30 weeks of pregnancy. She was referred to the emergency department of the Douala Laquintinie Hospital (DLH) from a health facility in the city after presenting with a penetrating wound of the abdomen resulting from a stab. It was associated with bowel protruding from the stab wound. Six hours prior to admission at the emergency room, the patient reports sliding and falling forward on the kitchen knife which she was holding. She noticed a wound in the peri-umbilical region with bowels protruding from the opening. The patient was taken to a health center where the loops were wrapped using wet gauze and subsequently transferred to us. Regarding the history of the patient, she has neither chronic diseases nor previous surgery; she has 6 healthy children from 6 previous pregnancies. She is at 30 weeks gestation. The follow-up of the pregnancy was done in a hospital of the city. She attended 4 prenatal consultations at the time of admission.

On admission, the primary assessment reported no airway obstruction, a tachypnea at 30 cycles per minute, oxygen saturation at $98 \%$, there were no signs of respiratory distress. The cardiovascular examination revealed hypotension at 90/56
mmHg with tachycardia at 112 beats per minute, extremities were warm, peripheral pulse was palpable, conjunctiva were pale. There was no external active bleeding. The patient was immediately placed in Trendelenburg with slight left lateral decubitus. Two large peripheral intravenous lines were placed and she received $2000 \mathrm{ml}$ of Ringer Lactate. There was an improvement and blood pressure was stabilized up to $108 / 86$ $\mathrm{mmHg}$; the pulse at 94 beats per minute and the respiratory rate at 28 cycles per minute. We classified bleeding in this patient as class II hemorrhage with a good response to fluid resuscitation.

At the secondary survey, the loco regional examination showed an enlarged abdomen with a gravid uterus, the fundal height was measured at $28 \mathrm{~cm}$. After removal of the gauze from the health center, the presence of viable bowel was noted (Figure $1 \mathrm{~A})$. Bowel protrusion was through a longitudinal abdominal wound about $3 \mathrm{~cm}$ long and located above the umbilicus (Figure 1B). There was an intestinal perforation of $3 \mathrm{~cm}$ wide. The abdomen was not sensitive, there was no uterine contracture. The patient no longer felt the active fetal movements; there was no fetal heart sound on Doppler. The vaginal examination was normal. There were no other anomalies noted during the secondary survey.

At the end of the clinical assessment, we concluded on a penetrating wound of the abdomen by a knife, complicated with evisceration, intestinal perforation and in utero fetal death in a patient with hemodynamic instability. Further resuscitation measures consisted of placing a urinary catheter, Paracetamol as an analgesic, an antibiotic prophylaxis and monitoring. We also administered anti-tetanus serum; the bowels were covered by new wet gauze using $0.9 \%$ isotonic saline solution. The pretherapeutic biological workup showed anemia at $9.8 \mathrm{~g} / \mathrm{dl}$. The other tests were within normal limits.

The patient was immediately transferred to the operating room for laparotomy. Initial indications were evisceration, intestinal perforation and hemodynamic instability. No morphological investigations were done yet. In the operating room, the patient was placed supine with a slight left-hand roll; we performed a general anesthesia with orotracheal intubation.

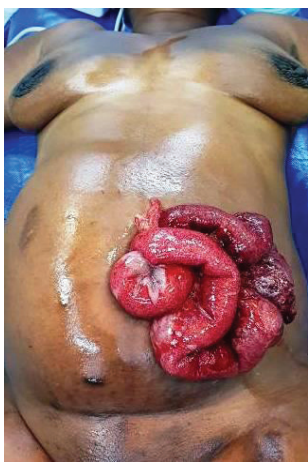

(A)

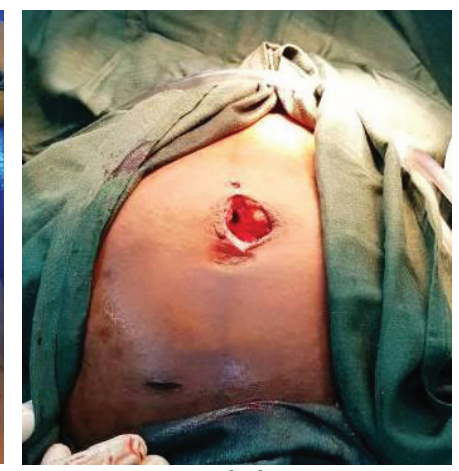

(B)
Figure 1: Protrusion of bowels through an umbilical wound

A: Evisceration

B: appearance of the abdominal wound after integration of eviscerated bowels. 
The first operative step consisted of an exploration of the protruding loops, on which we identified a viable loop with jejunal wound of $3 \mathrm{~cm}$ (Figure $2 \mathrm{~A}$ ) on the anti mesenteric edge. The wound was sutured transversely by a $3 / 0$ Vicryl $\subset$ suture (Figure $2 \mathrm{~B}$ ). Thorough intestinal toileting of the eviscerated bowels was done using isotonic normal saline, followed by the reintegration of bowels. The second operative step consisted in making a median incision. The exploration of the abdominal cavity showed the presence of a gravid uterus with a medial longitudinal perforation of $3 \mathrm{~cm}$ with the fetal scalp visualized (Figure 3). We performed a low transverse segmental hysterotomy; which allowed the extraction of a dead male fetus of 2400 grams; we noted a right basal penetrating thoracic laceration of $2 \mathrm{~cm}$ (Figure 4). Subsequently we performed the delivery of the placenta which was macroscopically normal and then a second exploration of the abdominal cavity was done, supplemented by an abdominal toileting.

Surgeons, anesthesiologists, obstetricians and psychologists have contributed to postoperative care; which consisted of the administration of oxytocin, analgesics. Antibioprophylaxy was continued for 48 hours; bromocriptin was administered to suppress lactation. The first wound dressing was done on postoperative day 4. The patient also benefited from psychological support. She was discharge on postoperative day 7 with oral iron, external psychological and gynecological follow-up.

\section{Discussion}

The occurrence of trauma in general during pregnancy is not a rare event as it occurs in one out of 12 cases [13],

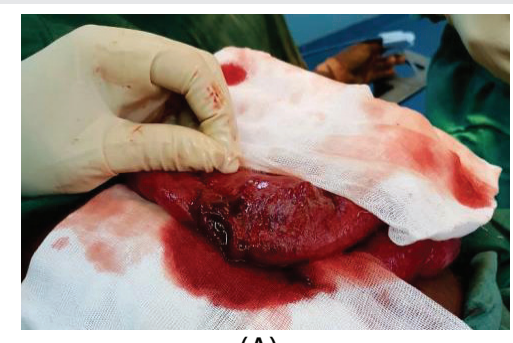

(A)

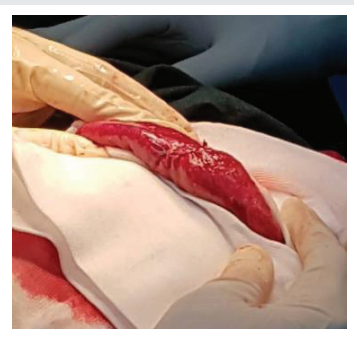

(B)
Figure 2: Eviscerated intestinal loop A: jejunal transfixing wound

$\mathrm{B}$ : appearance after resection and anastomosis

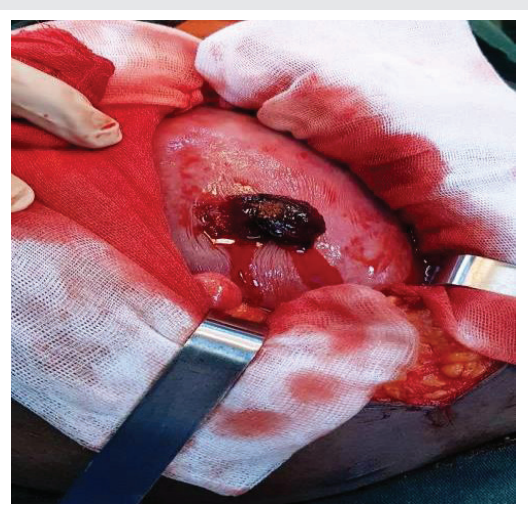

Figure 3: Uterine perforation and protrusion of the fetal scalp.

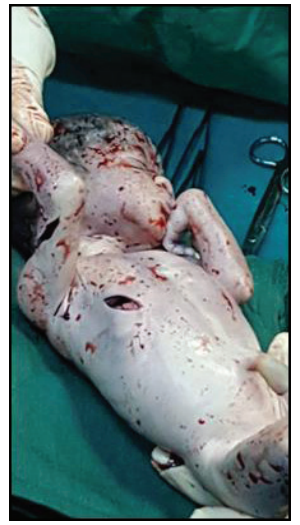

Figure 4: Fetal penetrating chest injury

road traffic accidents and domestic violence represent the predominant traumatic mechanisms $[15,16]$. According to Petrone [17], study published in 2010 on abdominal trauma in pregnant women, blunt trauma accounted for $91 \%$ of cases and abdominal wounds in $9 \%$ of cases. In the case presented here, it was a penetrating wound of the abdomen by a kitchen knife as a result of a domestic accident.

In non-pregnant women, the most affected organs are the small intestine, the colon, the liver, the vascular structures [19]. In pregnant women, intestinal lesions are rare, surpassed by uterine involvement. the development of the uterus out of the pelvis as early as the 12th week of gestation implies that the majority of penetrating wounds of the abdomen in the anterior zone are accompanied by uterine lesions $[20,21]$. These lesions may be responsible for fetal death directly from fetal injury or indirectly from hemodynamic instability in the mother. Petronius [17] reports a $16 \%$ fetal mortality after abdominal trauma in the pregnant woman, this frequency increases to $73 \%$ when it is a penetrating wound of the abdomen. In the clinical case presented, the spectrum of lesions is multiple and comprising of: evisceration, intestinal injury, perforation of the uterus associated with fetal chest injury and in utero fetal death.

Management in a trauma center showed a positive effect in reducing mortality and morbidity [10], of traumatized patient. The presence of an abdominal trauma in pregnancy necessitates therefore a multidisciplinary approach where obstetricians, surgeons, intensive care units, radiologists act together to ensure the well-being of the mother and fetus and this without delay. In the case thus reported, we note a delay in the time of management with an initial stop in a $3^{\text {rd }}$ category center. In this center, the eviscerated loop has been wrapped and moistened in sterile gauze; this is the first step to be made by any health care personnel in front of an evisceration.

Once at the surgical emergency; the reception and primary assessment was done by a surgeon. Faced with the absence of active fetal movements and the absence of fetal heart sounds, the morphological assessment was of no interest, the urgent indication for surgery was in the presence of evisceration, perforation and initial hemodynamic instability (although taken cared by primary resuscitation). Indeed, the management 
of abdominal trauma in patients with penetrating lesions has evolved during the last 100 years [19]. Before the $1^{\text {st }}$ world war, the behavior was conservative or expectation, which often resulted to death. During the First World War, laparotomy became the treatment of choice. Around the 1950, laparotomy became routine in the management of penetrating wounds of the abdomen. In recent decades, the advent of diagnostic and imaging procedures such as diagnostic peritoneal lavage, laparoscopy, ultrasound and CT have helped to change the algorithm for the management of penetrating trauma. To date, the formal indications of immediate laparotomy in case of penetrating lesions are: hemodynamic instability, peritonitis, evisceration and digestive tract hemorrhage [22]. Contrary, the operative decision will be assisted by imaging, preceded by wound exploration and repeated clinical examinations [23]. In pregnant women, even in cases of minor trauma, the clinical evaluation at the primary and secondary assessment should both look for non-obstetric, obstetrical and signs of fetal distress $[12,18]$. Once the assessment of the lesions is established, the management will depend on lesions found, ranging from simple materno-fetal monitoring [12], to caesarean section, or an emergency laparotomy in a trauma center with a multidisciplinary team [18].

\section{Conclusion}

The occurrence of abdominal trauma during pregnancy is a serious and potentially lethal medical condition for the mother and fetus. It imposes urgent and multidisciplinary care in an appropriate care unit with a neonatology center nearby. The primary and secondary survey will be exhaustive and as precise as possible, the treatment will have to be in agreement with the objectified injuries in order to guarantee the maternal and fetal well-being as much as possible.

\section{Acknowledgements}

The authors would like to thank all the clinicians and staff of the Douala Laquintinie Hospital for the care of the patient.

\section{Ethical considerations}

Written informed consent was obtained from the patient for publication of this case report and any accompanying images.

A copy of the written consent is available for review by the Editor-in-Chief of this journal.

Any identifying material has been removed, including the patient's name, date of entry, face or any distinctive features on the pictures taken.

\section{Authors 'contributions}

$\mathrm{OO}$ and TWL, contributed in design of the study and writing of the manuscript NJ, DG, BU, EJP, contributed in critical reading TWL, collected the pictures, and obtained the patient's consent.

All authors have read and approved the final version of the manuscript.

\section{References}

1. WHO (2018) Disease burden and mortality estimates [Internet]. Link: https://goo.gl/Q7yLX2

2. Gross CP, Anderson GF, Powe NR (1999) The Relation between Funding by the National Institutes of Health and the Burden of Disease. N Engl J Med 340: 1881-1887. Link: https://goo.gl/ZfyrHg

3. Memoire Online (2018) Motifs des consultations chirurgicales a l'unité des urgences de la clinique Bondeko - Edison NSIAMUNU. Link: https://goo.gl/P43byD

4. WHO (2018) Global status report on road safety 2015. Link: https://goo.gl/tynkFt

5. Song IG, Lee JS, Jung SW, Park JM, Yoon HD, et al. (2016) Analysis of Abdominal Trauma Patients Using National Emergency Department Information System. J Trauma Inj 29: 116-123. Link: https://goo.gl/HYPxxV

6. Hemmila MR, Wahl WL (2018) Chapter 13. Management of the Injured Patient. In: Doherty GM, editor. CURRENT Diagnosis \& Treatment: Surgery [Internet]. 13th ed. New York, NY: The McGraw-Hill Companies; 2010. Link: https://goo.gl/pzaeJj

7. Gad MA, Saber A, Farrag S, Shams ME, Ellabban GM (2012) Incidence, Patterns, and Factors Predicting Mortality of Abdominal Injuries in Trauma Patients. North Am J Med Sci 4: 129-134. Link: https://goo.gl/u8rZD6

8. Mnguni MN, Muckart DJJ, Madiba TE (2012) Abdominal Trauma in Durban, South Africa: Factors Influencing Outcome. Int Surg 97: 161-168. Link: https://goo.gl/NcsXE7

9. Velidedeoğlu E, Ozdemir A, Ozenç A, Onat D, Sanaç Y (1992) Factors affecting postoperative mortality in abdominal trauma. Int Surg 77: 198-202. Link: https://goo.gl/MSdBg2

10. MacKenzie EJ, Rivara FP, Jurkovich GJ, Nathens AB, Frey KP, et al. (2006) A national evaluation of the effect of trauma-center care on mortality. $\mathrm{N}$ Engl $\mathrm{J}$ Med 354: 366-378. Link: https://goo.gl/SisMTu

11. Aldemir M, Taçyildiz I, Girgin S (2004) Predicting factors for mortality in the penetrating abdominal trauma. Acta Chir Belg 104: 429-434. Link: https://goo.gl/XFKQLJ

12. Murphy NJ, Quinlan JD (2014) Trauma in Pregnancy: Assessment, Management, and Prevention. Am Fam Physician 90: 717-722. Link: https://goo.gl/r8dMSW

13. Hill CC, Pickinpaugh J (2008) Trauma and surgical emergencies in the obstetric patient. Surg Clin North Am 88: 421-440. Link: https://goo.gl/kpaxRE

14. Fildes J, Reed L, Jones N, Martin M, Barrett J (1992) Trauma: the leading cause of maternal death. J Trauma 32: 643-645. Link: https://goo.gl/CrG2s2

15. Mendez-Figueroa H, Dahlke JD, Vrees RA, Rouse DJ (2013) Trauma in pregnancy: an updated systematic review. Am J Obstet Gynecol 209: 1-10. Link: https://goo.gl/wHzEqb

16. Alkış I, Karadaş S, Karaman E, Gülşen İ, Öncü R, et al. (2014) Maternal and Fetal Outcomes of 179 Traumatised Pregnants in Teritary Referral Center Open J Obstet Gynecol 04: 1037-1043. Link: https://goo.gl/cQ1RtY

17. Petrone $P$, Talving $P$, Browder T, Teixeira PG, Fisher O, et al. (2011) Abdominal injuries in pregnancy: a 155-month study at two level 1 trauma centers. Injury 42: 47-49. Link: https://goo.gl/ECzaMK

18. Jain V, Chari R, Maslovitz S, Farine D, Maternal Fetal Medicine Committee, et al. (2015) Guidelines for the Management of a Pregnant Trauma Patient J Obstet Gynaecol Can JOGC J Obstet Gynecol Can JOGC 37: 553-574. Link: https://goo.gl/KWrnpc 
19. Patrick Offner (2017) Penetrating Abdominal Trauma Treatment \& Management: Approach Considerations, Prehospital Care, Surgical Therapy. Link: https://goo.gl/b8vqvJ

20. Petrone P, Asensio JA (2006) Trauma in pregnancy: assessment and treatment. Scand J Surg SJS Off Organ Finn Surg Soc Scand Surg Soc 95: 4-10.

21. Mattox KL, GoetzI L (2005) Trauma in pregnancy. Crit Care Med 33: S385-389. Link: https://goo.gl/CwA7Ca
22. Colwell C, Moore EE (2018) Initial evaluation and management of abdominal stab wounds in adults. In: UpToDate. Waltham, MA: Up To Date Inc. Link: https://www.uptodate.com

23. Inaba K, Okoye OT, Rosenheck R, Melo N, Branco BC, et al. (2013) Prospective evaluation of the role of computed tomography in the assessment of abdominal stab wounds. JAMA Surg 148: 810-816. Link: https://goo.gl/euqFwK

Copyright: (c) 2019 Oumarou 0, et al. This is an open-access article distributed under the terms of the Creative Commons Attribution License, which permits unrestricted use, distribution, and reproduction in any medium, provided the original author and source are credited. 